\title{
Species limits in the Elegant Pitta (Pitta elegans) complex from Wallacea based on bioacoustic and morphometric analysis
}

\author{
Arya Y. Yue ${ }^{1,2}$, Elize Y. X. Ng ${ }^{2}$, James A. Eaton ${ }^{3}$ and Frank E. Rheindt ${ }^{2 *}$
}

\begin{abstract}
Background: The Elegant Pitta (Pitta elegans) complex displays a remarkable diversity of morphological and bioacoustic traits across five taxa currently recognized as subspecies. They differ in plumage characteristics (such as red versus black belly patches; supercilium color and extent; and white versus black throats), in lifestyle (resident versus migratory) and in vocalizations. We investigated the morphological, bioacoustic and ecological differences across all taxa after recent studies demostrated the importance of these traits in recognizing biological species limits across pittas.

Methods: Morphometric analysis was carried out by measuring tarsus, wing, tail and bill lengths of 15 specimens at the Natural History Museum, UK, and plumages were inspected across 106 unique individuals from four different repositories. Bioacoustic analysis was based on 134 range-wide sound recordings. Two types of calls, territorial calls and alarm calls, were analyzed using different sets of parameters. Principal component analysis and the Isler Criterion were applied to the measurements. Playback trials were conducted to explore the levels of response of each taxon to the call types of the other taxa.
\end{abstract}

Results: The territorial call of concinna exhibits a distinct two-element motif, while elegans, maria and virginalis utter a three-element motif in which the first two elements are given in quick succession. On the other hand, vigorsii, produces both two-element and three-element motifs with longer breaks in between elements. As further corroborated by the playback trials, the three taxa elegans, virginalis and maria form a tight vocal cluster, whereas each concinna and vigorsii are distinct. The alarm call turned out to be less diagnostic even though most taxa did roughly separate into different vocal clusters. Morphometric analysis failed to produce strong differences, but plumage distinctions among multiple taxa are pronounced.

Conclusions: We suggest splitting the Elegant Pitta into three biological species based on bioacoustic and-less so_- plumage evidence: (1) Temminck's Elegant Pitta P. elegans (including subspecies elegans, virginalis and maria), (2) Wallace's Elegant Pitta P. concinna (monotypic), and (3) Banda Elegant Pitta P. vigorsii (monotypic).

Keywords: Bioacoustic analysis, Elegant Pitta, Morphometric analysis, Pitta elegans, Territorial calls

*Correspondence: dbsrfe@nus.edu.sg

2 Department of Biological Sciences, National University of Singapore, 16 Science Drive 4, Singapore 117558, Singapore

Full list of author information is available at the end of the article

\begin{abstract}
Background
Pittas (Pittidae) are arguably the most well-known family of suboscine songbirds in the Old World. Their colorful and brilliant plumage, coupled with their shy terrestrial lifestyle as denizens of the forest interior, made them a coveted target for early bird collectors and explorers in the 19th century (Wallace 1872), and they continue
\end{abstract}


to elicit fascination by ornithologists willing to go to extreme lengths to study them (Gooddie 2010). While relationships among pitta species are generally wellestablished (Irestedt et al. 2006), the exact number of pitta species remains contentious over disagreements about the way in which species limits are drawn. A number of recent studies have presented genetic, morphological and bioacoustic data that suggest the recognition of additional species within the Red-bellied Pitta (Erythropitta erythrogaster) complex (Irestedt et al. 2013; Collar et al. 2015), the Hooded Pitta (Pitta sordida) complex (Ericson et al. 2019) and the Banded Pitta (Pitta guajana) complex (Rheindt and Eaton 2010), with continuing disagreement in global bird checklists and regional field guides over the acceptance of some of these proposals (Dickinson et al. 2014; Pratt and Bruce 2014; Eaton et al. 2016; Clements et al. 2020; Handbook of the Birds of the World and Bird Life International 2019; Gill et al. 2020).

The Elegant Pitta (Pitta elegans) displays a remarkable diversity of morphological and bioacoustic traits across five taxa currently recognized as subspecies (Fig. 1). Its variability has been neglected in taxonomic circles relative to that of other pitta species complexes, probably because of its remote distribution centered on the Lesser Sundaic archipelago in Wallacea (eastern Indonesia). The five taxa differ considerably, not only in conspicuous plumage characters (such as red versus black belly patches and white versus black throats), but also in lifestyle: while most of them are resident inhabitants of seasonal monsoon forests and woodland of their respective home islands, the nominate form elegans, which breeds on the driest islands, is migratory and deserts its breeding locations for 'wintering grounds' (Eaton et al. 2016; Erritzoe and de Juana 2020). The presence of both residents and obligate migrants within one species complex is akin to the situation in the Hooded Pitta from mainland Asia to Papua New Guinea (Ericson et al. 2019).

In the present study, we revisit species limits across the five taxa of the Elegant Pitta. Our integrative approach relies on a combination of characters, including plumage, morphometrics, and bioacoustics. We discuss taxon-specific differences against the backdrop of the unique earth history of the Lesser Sundaic island chain that is home to this species complex. Our taxonomic assessment is

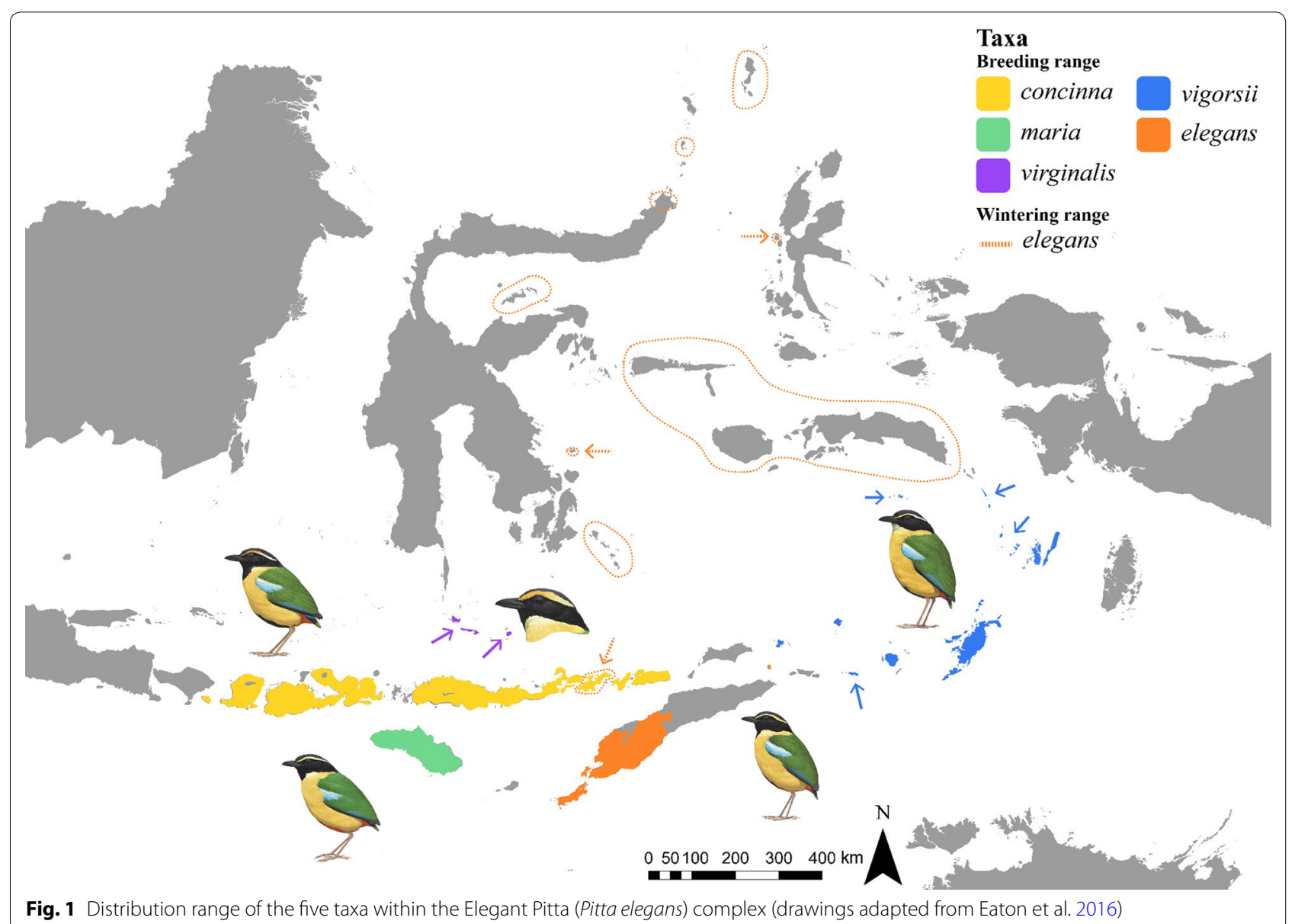


guided by recent insights into the importance of not only plumage and morphology but also bioacoustic differences as indicators of species status in pittas (Rheindt and Eaton 2010; Ericson et al. 2019) while adopting the tenets of the "multidimensional biological species concept" (Mayr 1996), an updated version of modern biology's first species concept (Mayr 1942, 1969), which continues to be the most widely applied such concept in biology. In our application of this species concept, we resort to the "yardstick approach" (Mayr and Ashlock 1991), which compares the magnitude of differences between target populations with differences between members of closely related, well-studied species pairs whose status as independent species is not in doubt.

\section{Methods}

\section{Morphometric and plumage analysis}

Measurements of tarsus, wing, tail and bill lengths were taken of specimens at the Natural History Museum (NHM) at Tring, UK (Additional file 1: Table S1). The 15 individuals measured included six specimens of concinna, four maria, one vigorsii, three nominate elegans, and one virginalis. Measurements were taken by a single person (JAE) to preclude observer bias. All specimens thus measured were adults, except one immature elegans from Lomblen (Additional file 1: Table S1), recognized solely through its orange gape. This latter specimen did not emerge with an unusual biometric profile, which is unsurprising given its migratory status outside the known breeding range, indicating that it was fully grown. The specimen series included six males, six females, and three unsexed specimens. The low sample size per taxon precluded a separation of measurements into different sexes for significance testing, but allowed for principal component analysis (PCA) using the 'prcomp' function in $R$ version 3.6.0 ( $R$ Core Team. R 2019), with the PCA plot drawn using the "ggplot2" package.

The same NHM specimens were photographed and inspected for plumage traits (Additional file 2: Figs. S1-3). In order to improve our sample size for plumage comparison, we additionally inspected the archival photos of 32 specimens available in the digital photo collection of Naturalis (Leiden, Netherlands) (Additional file 3: Table S2) - not including the material for two fledglings or young juveniles-at the following source: https://biopo rtal.naturalis.nl/result/multimedia $/$ ter $\mathrm{m}=$ pitta + elega ns\&size $=100 \&$ from $=0$. This photo archive depicts individuals from conclusive angles that permit a verification of most to all plumage traits every time. We further checked through all 15 photos of unique individuals (not counting duplicates) of Elegant Pittas available at the time in the public Oriental Bird Images (OBI) database (https ://orientalbirdimages.org/) and scrutinized an additional
44 photos of unique individuals deposited in the public eBird database (www.ebird.org) (Additional file 4: Table S3). These sets of OBI and eBird photos did not include fledglings and young juveniles, but did include older immatures recognizable through their orange gapes (Additional file 4: Table S3). In summary, our plumage comparison among taxa was based on a cumulative total of 106 pitta individuals from four different repositories. These are broken up into 5 immatures (confirmed through their orange gapes) and 101 adults. Sexing was not possible on the OBI and eBird photos (see Results).

\section{Bioacoustic sampling}

In total, 134 sound recordings were compiled from across all five taxa (Additional file 5: Tables S4-6). These had been made by 21 different recordists in the field and include 72 recordings (including 54 territorial and 18 alarm calls) deposited with the public sound library xeno-canto (www.xeno-canto.org), 16 recordings (including 12 territorial and 4 alarm calls) deposited with the Macaulay Library (http://macaulaylibrary.org), 14 recordings (including 10 territorial and 4 alarm calls) with the Avian Vocalizations Center (AVoCet) (avocet.integrativebiology.natsci.msu.edu), two recordings (one territorial and one alarm call) with the Internet Bird Collection (www.hbw.com/ibc), as well as 30 recordings (including 22 territorial and 8 alarm calls) made by JAE and/or R.O. Hutchinson (available upon request from JAE) (Additional file 5: Tables S4-6). The recordings were converted from mp3 to WAV format, if applicable, in order to be analyzed using Raven Pro 1.5 (Bioacoustics Research Program, Cornell Laboratory of Ornithology, Ithaca, NY, USA).

\section{Bioacoustic analysis}

The Elegant Pitta has two main types of vocalizations: a nasal, one-syllable alarm call and a geographically variable multi-syllabic territorial or courtship call (Fig. 2; Additional file 5: Tables S4, S5). Recordings of these two types of vocalizations were analyzed separately using different sets of parameters tailored to each of them. Sonograms of each recording were adjusted to a roughly equal contrast between background noise and the birds' calls. The window size was set to 1000. After excluding three pitta recordings containing vocalizations that were not homologous with either the alarm call or territorial call, and further removing five recordings whose quality was too poor (Additional file 5: Table S6), we arrived at a final dataset of 134 recordings.

We interpreted a single trace on a sonogram as an 'element' and a temporally cohesive collection of elements as a motif, in alignment with previous bioacoustic analyses (Nemeth and Brumm 2010; Rheindt et al. 2011; Nemeth 


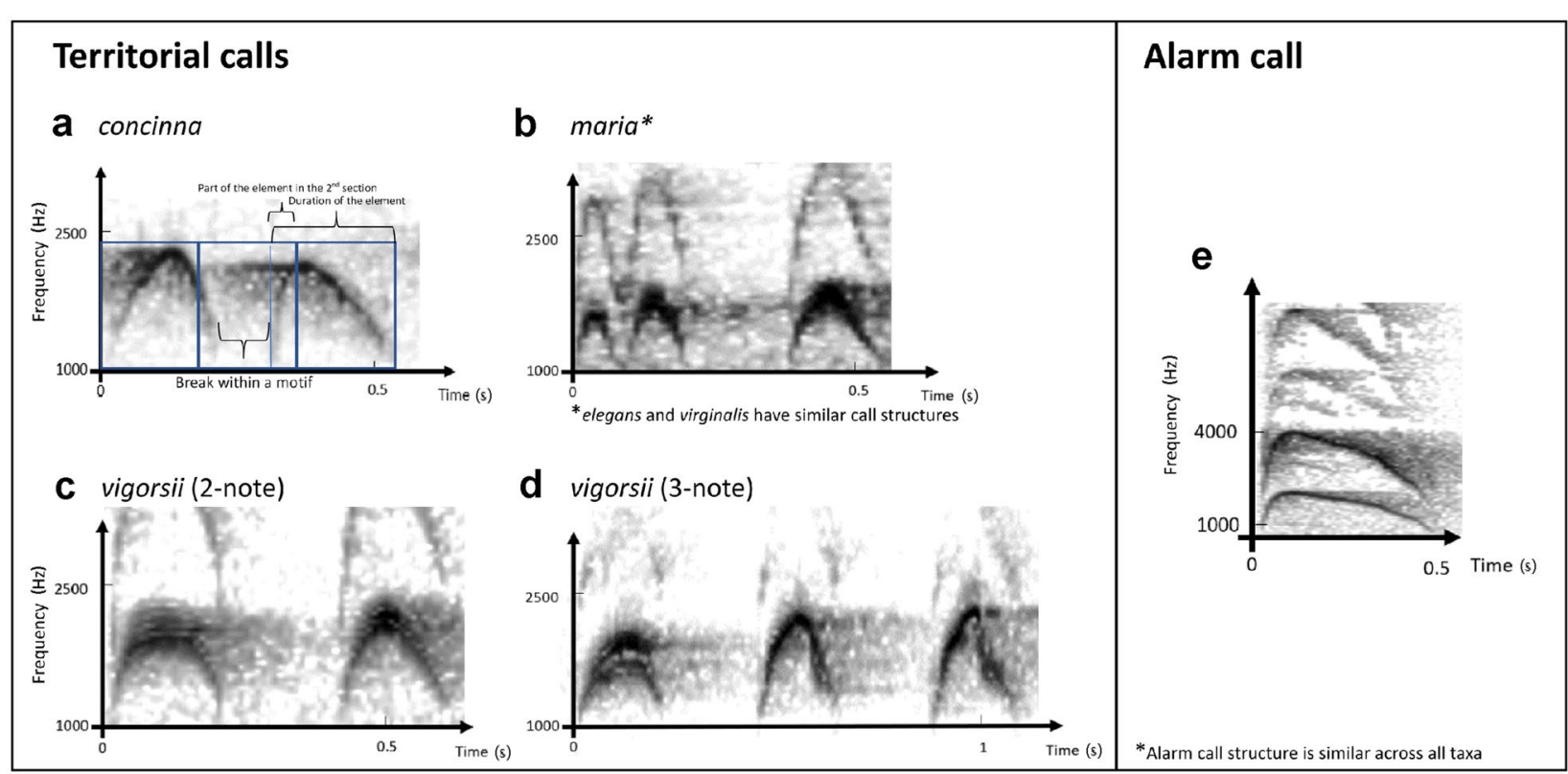

Fig. 2 Sonograms of four different territorial calls (left box) and one alarm call (right box) of various taxa. a Thick blue boxes illustrate the division of a motif into three equal time sections for analytical purposes with recording XC292445 [concinna]. Territorial call sonogram of b XC115283 [maria]; $\mathbf{c}$ RH3 [vigorsii, 2 note variant]; d XC417506 [vigorsii 3 note variant]. e Sonogram of alarm call of AV19281 [elegans]. Note that alarm calls across all taxa are similar. Accession numbers refer to specific recordings as listed in Additional file 5: Table S4, S5

et al. 2013; Harris et al. 2014). Recordings containing more than one calling bird were analyzed for each bird individually if unequivocal.

For analytical purposes, each motif of the territorial calls was divided into three equal sections by time (Fig. 2). We measured 13 parameters for territorial calls, including (1) the number of elements per motif; (2) motif duration; (3) percentage of break or gap per motif (derived from duration of break(s) within a motif divided by motif duration); (4) number of elements per second (i.e. number of elements divided by duration); (5) the lowest frequency; (6) the highest frequency; (7) band width (the highest frequency minus the lowest frequency), (8) center frequency as measured by Raven Pro (=frequency tranche with the most amount of black); (9) peak frequency as measured by Raven Pro (calculated from the darkest pixel within call); (10) change in percentage of break from 1st to 2nd time sections, which is: (the duration of break(s) in 2nd section [see Fig. 2 for illustration] minus duration of break(s) in 1st section) divided by duration of one section; (11) change in percentage of break from 2nd to 3rd section; (12) change in element duration from 1st to 2nd section, which is: (the cumulative duration of all parts of element(s) that fall within the 2nd section divided by the cumulative duration of all these element(s)) [see Fig. 2 for illustration] minus (the cumulative duration of all parts of element(s) that fall within the 1st section divided by the cumulative duration of all these element(s)); and (13) change in element duration from 2nd to 3rd section (Fig. 2).

Alarm calls were often characterized by harmonics (Fig. 2). In this study, only the main (=the lowest) harmonic was measured even when the second lowest was the clearest. The alarm calls were analyzed with a different set of parameters. We divided the sonogram into four equal time sections and measured nine parameters, including (1) motif duration; (2) the lowest frequency; (3) the highest frequency; (4) band width (the highest frequency minus the lowest frequency); (5) center frequency (=frequency tranche with the most amount of black); (6) peak frequency (calculated from the darkest pixel within a call); (7) change in center frequency from 1st to 2 nd quarter; (8) change in center frequency from 2nd to 3rd quarter; and (9) change in center frequency from 3rd to 4th quarter.

Taxon assignment for recordings not made by ourselves was initially guided by locality, although we later detected one incident of a mislabeled locality (AVoCet recording: AV16462). Recordings made by JAE were confirmed by visual identification. Bioacoustic measurements for each parameter were averaged across all motifs produced by the same individual. From the 134 recordings, we obtained 99 sets of measurements for territorial calls (44 concinna, 14 elegans, 15 maria, 12 vigorsii, 11 
virginalis and 3 migrants initially unassigned) and 35 sets of measurements for alarm calls (9 concinna, 10 elegans, 5 maria, 6 vigorsii, 1 virginalis, and 4 migrants initially unassigned) (Additional file 5: Tables S4, S5).

PCA was carried out for territorial calls and alarm calls separately across all taxa using the 'prcomp' function in $\mathrm{R}$ version 3.6.0 (R Development Core Team 2019), with the PCA plots drawn using the "ggplot2" package. For territorial calls, 95\% confidence ellipses were applied to data clusters.

A bioacoustic diagnosability test, here called the Isler Criterion (Isler et al. 1998), was applied to the bioacoustic data to assess whether any of the parameters were vocally diagnosable (Table 1). This test has been specifically designed for suboscine passerines (Isler et al. 1998), of which pittas are the most prominent Old World representative, although it has successfully been applied to a wide variety of other passerines and non-passerines in the meantime, including across Asia (Sangster and Rozendaal 2004; Ng and Rheindt 2016; Ng et al. 2016; Cros and Rheindt 2017; Gwee et al. 2019). As a vocal diagnosability test, it is more stringent and discerning than simple significance tests or effect size tests (Isler et al. 1998) because it requires two strict criteria to be fulfilled for the vocalizations of two populations to be considered diagnosable: (1) the ranges of parameter measurements must not overlap between population "a" and population " $\mathrm{b}$ ", and (2) the following equation must be satisfied:

$$
\overline{x_{a}}+t_{a} S D_{a}<\overline{x_{b}}-t_{b} S D_{b}
$$

in which SD is the standard deviation of a parameter's measurements for populations "a" (i.e., the population with the smaller measurements) and "b" (i.e., the population with the larger measurements), $\bar{x}$ describes the mean of a parameter's measurements for populations "a" and "b", and $t$ is the Student's $t$-score at the 97.5th percentile for $N-1$ degrees of freedom, with $N$ being the sample size for each population, respectively.

\section{Playback trials}

To observe how individuals respond behaviourally to the playback of calls from other taxa, playback trials were conducted on an opportunistic basis by JAE over multiple years. Each taxon's vocalizations were played back to itself and to all other taxa to gauge the level of response. As an exception, no virginalis recording was played to maria as the former's calls were unknown at the time of the trials. The number of trials for each combination is given in Table 2.
The majority of playback trials were conducted using a Logitech $\times 50$ portable Bluetooth speaker and a Sony NW-A25 player. Sound recordings for each taxon used in the experiment were kept constant. The trials were conducted in the presence of a territorial individual by placing the speaker $\sim 10 \mathrm{~m}$ away from the partially concealed human observer while maintaining a line of sight with the bird and speaker. The calls were played for bouts of up to two minutes. During this period, the reaction of the target individual was recorded as one of the following: (1) no change in the bird's behavior; (2) responsivebird called back without moving towards the sound of the playback; (3) aggressively responsive-bird moved towards the sound of the playback, either by flying, hopping, or moving up to a more prominent perch.

\section{Results}

Territorial calls were characterized by extensive variability across the Elegant Pitta complex. The widespread taxon concinna, resident from Lombok to Alor with the exception of Sumba, exhibited a distinct two-element motif (Fig. 2). In contrast, most other taxa, including nominate elegans centered around Timor, maria and virginalis utter a three-element motif in which the first two elements are given in quick succession (Fig. 2). The only taxon displaying variability in this trait was the fareastern vigorsii, centered around the Tanimbar and Kai Islands, in which both two-element and three-element motifs were detected. However, neither of them resembled those given by the other taxa. Instead, vigorsii was characterized by a comparatively slow delivery of these elements with unusually long breaks in between, no matter whether the two-element or three-element call is implicated (Fig. 2).

PCA combining 13 parameters measured across the territorial calls shows the three taxa elegans, virginalis and maria forming a tight vocal cluster of three-element callers, whereas concinna-with its two-element call-is distinctly offset without overlap (Fig. 3). Unsurprisingly, the vocally variable vigorsii emerges in two separate clusters, neither of them overlapping with any other taxa, regardless of whether the two-element or three-element call of this taxon was recorded (Fig. 3). A number of territorial calls of migrants initially unidentified to taxon level were vocally embedded within the three-element call cluster of taxon elegans, to which migrants have conventionally been assigned (Fig. 3).

The Isler test result for territorial calls corroborates results from the PCA plot (Table 1). Pairwise comparisons between elegans vs maria, elegans vs virginalis and maria vs virginalis did not result in a single Isler-diagnosable parameter, while comparisons between concinna and other taxa as well as between vigorsii and other taxa 


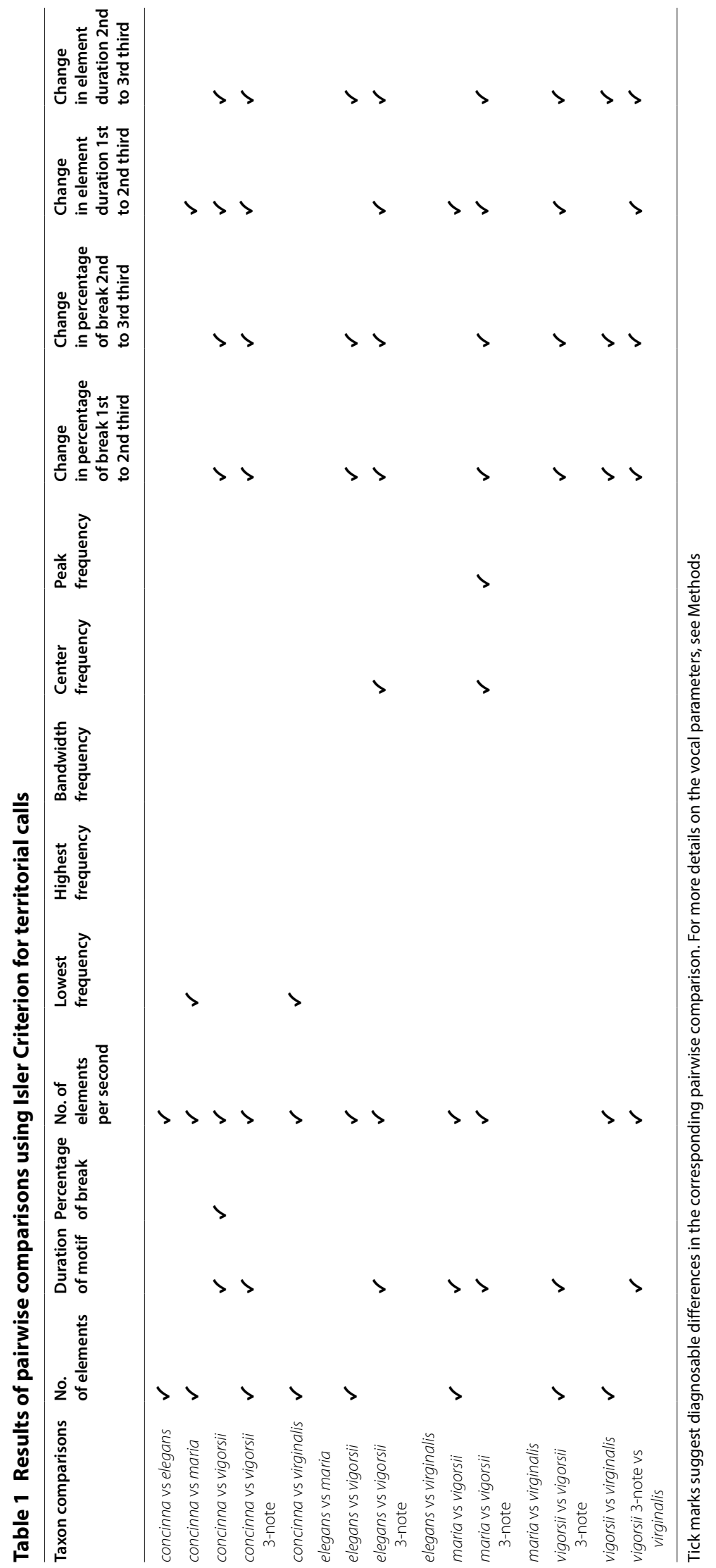


Table 2 Playback trial observations

\begin{tabular}{|c|c|c|c|c|c|}
\hline \multirow[t]{2}{*}{ Playback used } & \multicolumn{5}{|l|}{ Individual response } \\
\hline & elegans & virginalis & maria & concinna & vigorsii \\
\hline elegans & Aggressive $(n=50)$ & Aggressive $(n=10)$ & Aggressive $(n=5)$ & No $(n=10)$ & $\mathrm{No}(n=5)$ \\
\hline virginalis & Responsive $(n=5)$ & Aggressive $(n=15)$ & $\mathrm{N} / \mathrm{A}$ & $\mathrm{No}(n=10)$ & $\mathrm{No}(n=4)$ \\
\hline maria & Aggressive $(n=5)$ & Aggressive $(n=5)$ & Aggressive $(n=200)$ & No $(n=50)$ & Responsive $(n=10)$ \\
\hline concinna & $\mathrm{No}(n=15)$ & $\mathrm{No}(n=10)$ & $\mathrm{No}(n=50)$ & Aggressive $(n=300)$ & No $(n=10)$ \\
\hline vigorsii & $\mathrm{No}(n=5)$ & $\mathrm{No}(n=2)$ & $\mathrm{No}(n=10)$ & Responsive $(n=10)$ & Aggressive $(n=30)$ \\
\hline
\end{tabular}

"No" indicates no change in the bird's behavior upon playback. "Responsive" means that the bird called back without moving towards the source of the playback. "Aggressive" means the bird moved towards the source of the playback, either by flying, hopping, or moving up to a more prominent perch. N/A = no playback was attempted. Approximate sample sizes of playback trials $(n)$ are given for each combination; values of $n>5$ are rounded to the nearest 5 ; the two values of $n>100$ are rounded to the nearest 100 . Intra-taxon combinations had the highest sample sizes and, according to expectation, they invariably elicited an aggressive response

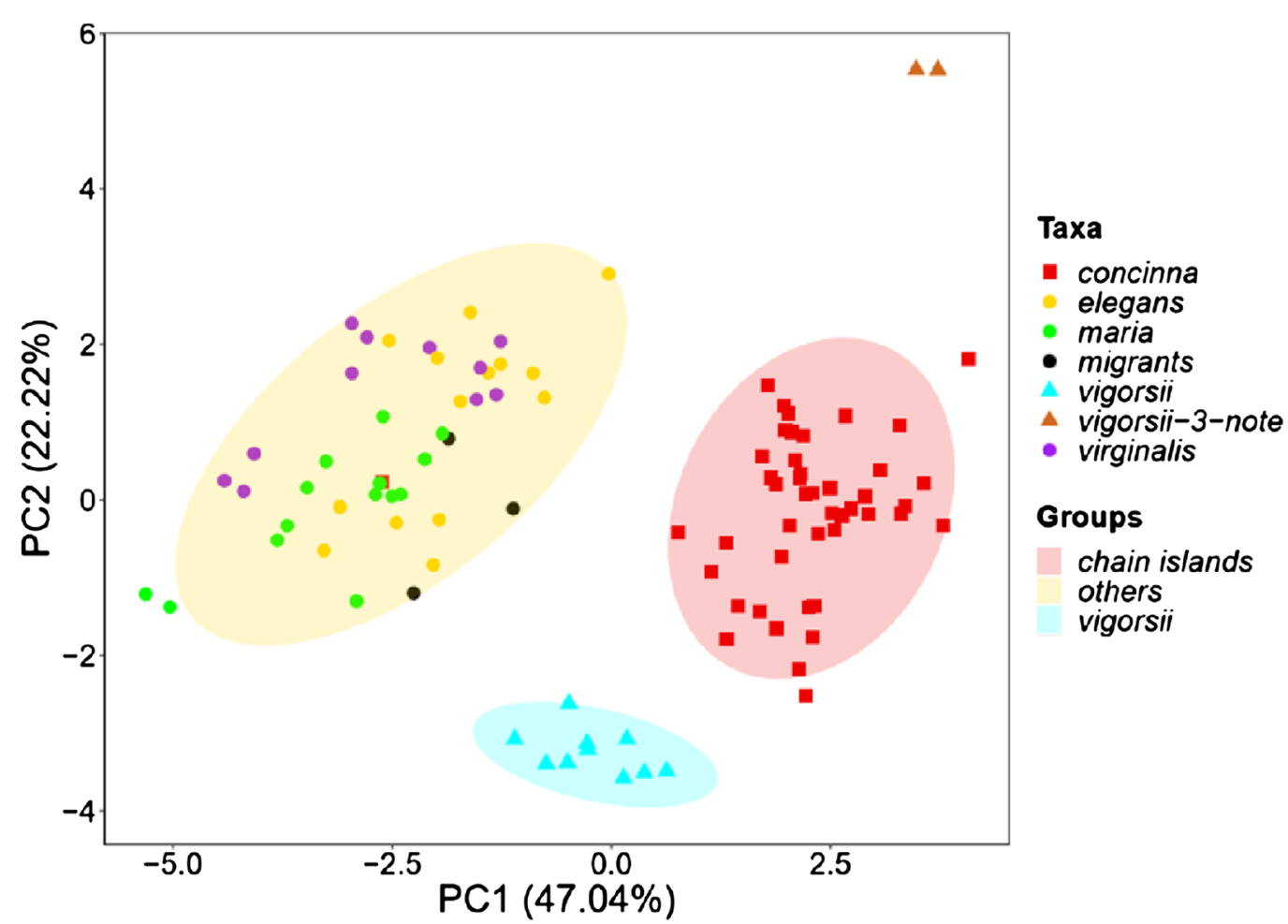

Fig. 3 Principal component analysis plot for territorial calls. An individual labeled "Puarlolo, Flores" (AV16462; red square within yellow cluster on plot) has meanwhile been determined to be a case of mislabeling (see text)

yielded multiple diagnosable parameters, suggesting a division into three vocally distinct groups comprising (1) concinna, (2) vigorsii, (3) and all remaining taxa (Table 1).

The alarm call turned out to be much less diagnostic than the territorial call, with PCA showing overlap among taxon clusters, even though most taxa roughly separated into different parts of the plot (Fig. 4).

For territorial calls, the number of elements per second emerged as the parameter that best differentiates vocal groups, followed by the number of elements, motif duration, the change in the percentage of breaks between call sections and the change in element duration between call sections (PC loadings available in Additional file 6: Tables S7, S8). Frequency parameters were notably less diagnostic, underscoring the greater value of temporal parameters as opposed to frequency parameters as a taxonomic marker in these birds, 


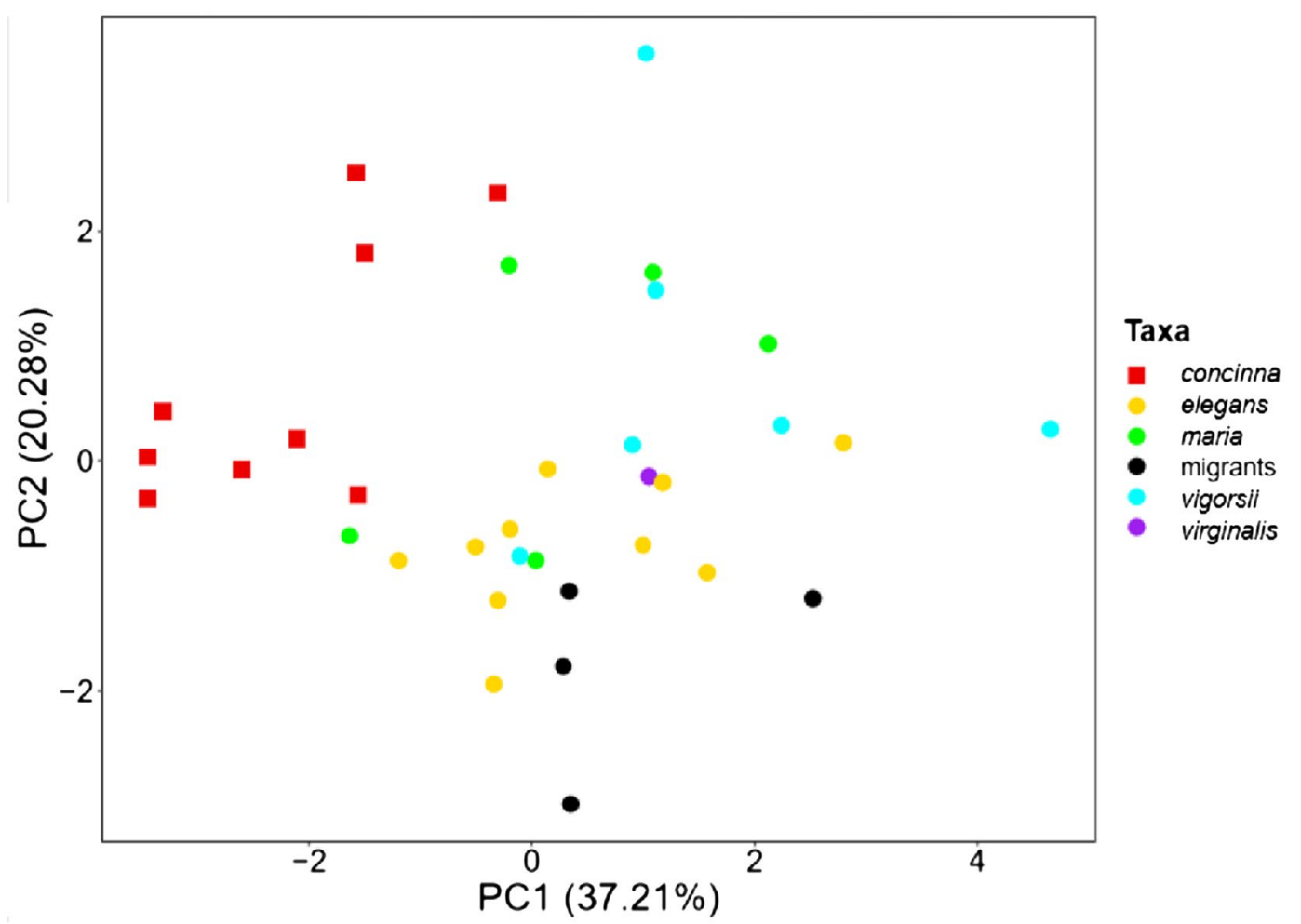

Fig. 4 Principal component analysis plot for alarm calls

corresponding to findings by Rheindt et al. (2011) and $\mathrm{Ng}$ et al. (2016) for Asian non-passerines.

The playback trials fully corroborated our quantitative bioacoustic analysis (Table 2). All taxa were observed to respond aggressively when calls of the same taxon were played. Taxa elegans, virginalis, and maria were reciprocally responsive-usually aggressively so-to playback of calls from the other two taxa, respectively. In contrast, concinna and vigorsii were largely unresponsive to calls from elegans, virginalis, and maria, with an exception of vigorsii mildly responding to calls from maria. The taxon concinna was observed to be mildly responsive to calls from vigorsii but not vice versa (Table 2).

The PCA plot for morphometric measurements remained inconclusive (not shown; measurements available in Additional file 1: Table S1). This result should be interpreted cautiously because of the low sample size of measurements and our inability to analyze biometrics separately for each sex.

Plumage inspection corroborated distinctions previously noted in the literature, pointing to strong differences in the colouration of the supercilium, belly patch, throat colour and wing patch among taxa (Table 3; Additional file 2: Figs. S1-3). These plumage differences among taxa emerged as constant and diagnostic-without exception-across a total of 106 pitta individuals considered on the basis of specimen material and/or photos (Additional file 2: Figs. S1-3; Additional file 3: Table S2; Additional file 4: Table S3). Visual inspection of these 106 unique pitta individuals also provided important new insights into plumage variability within each taxon. For instance, the 5 individuals that were in advanced immature stages (as recognized through their orange gapes) generally lacked any differences from the adult plumage of their respective taxon, with the possible exception of two immature elegans individuals in which the upper belly did not yet look completely blackish but retained some reddish coloration. Visual inspection of these 106 unique individuals also hinted at a complete lack of sexual dimorphism and seasonal variation, as indicated in the previous literature (e.g. Eaton et al. 2016). Although gender assignment was not possible in the case of photo material from public databases, the large breadth of visual material should have included an ample amount of both males and females that would have facilitated the detection of sex-related plumage differences if they had been present. 
Table 3 Plumage comparison across the Elegant Pitta complex

\begin{tabular}{|c|c|c|c|c|}
\hline Taxon & Throat & Supercilium & Belly patch & White wing patch \\
\hline concinna & Black bib extends to upper breast & $\begin{array}{l}\text { Rufous base, } \\
\text { contrasting with } \\
\text { white rear }\end{array}$ & Extensively black on upper belly, red on lower belly & Present \\
\hline elegans & Extensively black & Pale buff & Extensively red with small black upper belly extension & Present \\
\hline vigorsii & All-white & White & $\begin{array}{l}\text { Narrow patch extensively black on upper belly, red on lower } \\
\text { belly }\end{array}$ & Present \\
\hline virginalis & Black chin line under bill & Broad, rich buff & Extensively red with small black upper belly extension & Present \\
\hline maria & Extensively black & Pale buff & All-red & Not present \\
\hline
\end{tabular}

All given character states were observed to be constant across all adult specimens examined

\section{Discussion}

Our bioacoustic results yielded strong evidence for three distinct territorial call types across the Elegant Pitta species complex (Fig. 2; Table 1). These call types clearly separated on the basis of 13 parameters measured across all populations (Fig. 3), but are easy to diagnose even superficially and to the human ear. The first call type is composed of three elements in which the initial two elements are given in quick succession (Fig. 2b). This is the typical territorial call of the migratory nominate form elegans from Timor, Semau and Rote, but also of two resident taxa, virginalis from small islands in the Flores Sea as well as maria from Sumba. The second call type is composed of only two elements, and is uttered by the wideranging taxon concinna from Lombok, Sumbawa, Flores, Lomblen, Pantar, Alor and neighbouring smaller islands (Fig. 2a). Finally the last taxon vigorsii, which breeds on the Banda Sea islands of Kai Kecil, the Tanimbar islands and various extremely small island groups, is unique in exhibiting both two-element (Fig. 2c) and three-element calls (Fig. 2d), but neither of them particularly closely resembling any other taxa. Instead, both call renditions of vigorsii are much slower than those of other Elegant Pitta taxa. Differences in the alarm calls of Elegant Pittas appear less pronounced, although there were clear trends of separation across the nine alarm call parameters we measured (Fig. 4).

Suboscine passerines like pittas are not capable of song learning (Kroodsma and Byers 1991), rendering territorial calls of particular importance as a taxonomic marker. The vocal differentiation in Elegant Pittas detected in this study is extreme in comparison to that in other pittas. For example, pairs of sympatric pittas widely recognized as different species often have territorial calls of an identical syllable structure that can only be told apart by slight differences in timing and rhythm, but not in such basic parameters as the number of elements per motif, e.g. Mangrove Pitta (Pitta megarhyncha) and Blue-winged Pitta (Pitta moluccensis) (Eaton et al. 2016). The Banded
Pitta (P. guajana) complex was split into three species on the basis of much less pronounced vocal differences (Rheindt and Eaton 2010). Some modern treatments (del Hoyo and Collar 2016; Clements et al. 2020; Gill et al. 2020) but not others (Eaton et al. 2016) recognize over a dozen newly-split species within the Red-bellied Pitta complex despite an absence of properly documented vocal differentiation of the kind presented here. On the basis of this vocal evidence alone, when placed into the greater perspective of bioacoustic markers in pittas, we feel comfortable splitting the Elegant Pitta into three species:

1. Temminck's Elegant Pitta P. elegans (incl. subspecies elegans, virginalis and maria), named after Coenraad Jacob Temminck, the initial describer of the species complex;

2. Wallace's Elegant Pitta P. concinna (monotypic), named after Alfred Russel Wallace who procured the type material for this taxon;

3. Banda Elegant Pitta P. vigorsii (monotypic), named after the Banda Sea to which this narrowly-distributed species is restricted.

While we propose this taxonomic revision as the most conservative treatment based on current data available, we call for the addition of genetic analyses to corroborate these results. For instance, genetic data may well support an additional elevation to species level of maria, which is virtually indistinguishable from elegans in vocalizations (Figs. 2, 3; Table 1) but exhibits strong plumage differentiation (Table 3).

Wallace's Elegant Pitta P. concinna has the most extensive breeding range of these three species-level taxa, breeding along the main Lesser Sundaic chain of islands from Lombok all the way east to Alor over more than $1000 \mathrm{~km}$. However, many of these islands have been connected through land bridges during the global sea level recessions of the past few glacial periods, the last time as 
recently as $\sim 15,000$ years ago (Sarr et al. 2019), allowing the birds to connect via land. Even those islands that remained disconnected, such as Pantar and Alor, which are separated from Lomblen and Flores by deeper sea, would have seen the shortest overwater distance decrease from $\sim 10 \mathrm{~km}$ to $\sim 5 \mathrm{~km}$ because of receding sea levels. The contiguity of this island chain explains how $P$. concinna has managed to remain so homogenous across such vast space, and is now a monotypic species.

The monotypic Banda Elegant Pitta P. vigorsii breeds on small, disconnected island groups across a vast area of deep sea in the eastern Banda Sea. It remains the least well-known taxon in the Elegant Pitta complex, appearing to be seasonally vocal and difficult to locate during certain months throughout its range. It is remarkable both in terms of plumage, being the only taxon with no black on the throat, and in terms of bioacoustics, as it boasts two separate territorial call types (a two-element call and a three-element call) that can be given independently. We have confirmed in the field that one individual is capable of uttering both call types within a short time, confirming that these two call types are not an additional taxonomic marker within this species.

Temminck's Elegant Pitta P. elegans combines the greatest amount of variability, both in terms of morphology and ecology, even though its three constituent subspecies are vocally indistinguishable on present knowledge. While the nominate subspecies elegans, breeding on Timor and satellites between November and February, is a migrant, deserting its breeding grounds in the dry season and moving north into the Moluccas and Sulawesi between March and November, maria from Sumba is known as a year-round resident. Subspecies virginalis from a number of small islands in the Flores Sea is likely to be resident, too, although too few modern ornithologists have reached those islands to know for sure, with visits only between September and November (Eaton and Rheindt 2017). Its odd disjunct breeding distribution slightly south of Sulawesi (Fig. 1), relatively distant from the main breeding range of elegans, could be a product of a colonization drive by migratory elegans individuals that may have founded this breeding population in the Flores Sea. The red belly patch of maria (Sumba) stands in stark contrast with the black-and-red belly spot of elegans (Timor). Sumba and Timor are biogeographically disjunct and lack historic land bridges of any kind, suggesting that a further split of maria as a separate species may be warranted in the future. Genomic evidence will be needed to clarify this situation. In the meantime, however, we are comfortable with adopting a conservative approach, uniting maria, elegans and virginalis into one species to reflect their virtually identical territorial call in recognition of research results in other pitta complexes
(Ericson et al. 2019) indicating that call differences are more consistent with genomically defined species-level taxa than some plumage characters.

A number of recordings of migrants from the Sulawesi subregion as far north as the Talaud archipelago and Buru in the central Moluccan islands unsurprisingly aligned with the vocal cluster of three-element callers including nominate elegans from Timor (Fig. 3). Records, including specimens, from the central Moluccan islands and the Sulawesi subregion have for long been assigned to migratory elegans, and our vocal analysis confirms this (White and Bruce 1986). One recording from Puarlolo, Flores (AVoCet recording: AV16462), had been identified as concinna on the public database, presumably because of its locality, while our PCA placed this individual inside the cluster of elegans, maria, and virginalis (Fig. 3). A close review of this publicly available recording confirms that it clearly pertains to a three-element caller unlike all other sound examples hitherto produced for the population of concinna on Flores, including Puarlolo, which is a well-studied location. This apparently mislabeled individual must have been recorded elsewhere because multiple additional three-element callers can be heard in the background of this recording, along with other misplaced species such as a fulviventris Tenggara Whistler, which is endemic to Sumba.

Populations of elegans from Timor, Semau and Rote are known to migrate to the Sulawesi region in the dry season, presumably passing through Flores, which is roughly one third of the way in between, and thereby annually hopping across the range of the very different-sounding taxon concinna. A general lack of vocal records of elegans from islands such as Flores suggests, however, that these pittas largely remain silent during migration, rendering unlikely the simultaneous occurrence of multiple threeelement callers vigorously vocalizing at a well-known Flores location where only two-element calls have previously been recorded. On the other hand, one of the elegans specimens inspected at NHM (visually checked and confirmed by JAE) is from Lomblen, which is presumably the first confirmed record of a migrant elegans along the main Lesser Sunda chain, confirming that elegans passes through the range of concinna. Records of elegans are surprisingly sparse on their migratory routes, as there are still no records from Wetar, Atauro or even Timor Leste (Trainor et al. 2009), though it has been found to be locally numerous on its 'wintering grounds' (JAE pers obs.). The easternmost record of a nominate elegans during the breeding season is a specimen from Kisar, just to the east of Timor Leste.

Our taxonomic re-arrangement provides a more realistic assessment of species-level diversity across the Lesser Sunda islands. While Wallace's and Temminck's 
Elegant Pittas remain widespread, the Banda Elegant Pitta is inherently susceptible to habitat degradation because of its tiny breeding range. A conservation assessment of this species is urgently needed to guide conservation efforts.

Bioacoustics continues to be a robust technique that is used in taxonomic assesments across many avian lineages-passerines and non-passerines alike (e.g., Rheindt and Eaton 2010; Rasmussen et al. 2012; Collar et al. 2015; Gwee et al. 2019; Miller et al. 2020; Rheindt et al. 2020). A high level of congruence has been demonstrated for species delimitations based on bioacoustics and those based on genetic inquiries (e.g., Rheindt et al. 2008; Dong et al. 2015; Robin et al. 2017; Alström et al. 2018). Future genetic studies will be a welcome additional line of inquiry to confirm the patterns of Elegant Pitta differentiation here revealed.

\section{Supplementary information}

Supplementary information accompanies this paper at https://doi. org/10.1186/s40657-020-00227-4.

Additional file 1: Table S1. Summary of morphological measurements of museum specimens for the Elegant Pitta.

Additional file 2: Fig. S1. Photo of the underside of Elegant Pitta specimens. Fig. S2. Close up photo of the underside of Elegant Pitta specimens. Fig. S3. Photo of the side profile of Elegant Pitta specimens.

Additional file 3: Table S2. Elegant Pittas available in digital photo collection of Naturalis (Leiden, Netherlands).

Additional file 4: Table S3. Photos available from Oriental Bird Images and eBird.org.

Additional file 5: Table S4. Details of recordings and measurements made for territorial calls. Table $\mathbf{S 5}$. Details of recordings and measurements made for alarm calls. Table $\mathbf{S 6}$. Details of recordings that were excluded from analyses (for instructions on how to read accession numbers and corresponding repositories, see Additional file 5: Table S4).

Additional file 6: Table S7. Principal component (PC) loadings for PC analysis (PCA) on territorial calls. For information on call parameters, see Methods. Table S8. Principal component (PC) loadings for PC analysis (PCA) on alarm calls. For information on call parameters, see Methods.

\section{Acknowledgements}

We are indebted to all recordists who deposited their bioacoustic material in public sound databases, facilitating their use in this research. We would like to acknowledge the following sound databases for their important resources: Xeno-Canto, Macaulay Sound Library, Internet Bird Collection and Avian Vocalizations Center (AVoCet). We are indebted to Mark Adams at the Natural History Museum at Tring for allowing access to the specimens. We thank Rob Huthcinson for providing additional sound recordings.

\section{Authors' contributions}

FER and JAE conceived the study. JAE collected sound material in the field. AYY compiled all publicly available sound material under FER's guidance. AYY performed bioacoustic measurements under instructions by FER. AYY and EYXN analyzed bioacoustic data under guidance by FER. JAE inspected and measured specimens in the museum. AYY wrote a first draft of the manuscript, and all authors contributed to finalizing the manuscript. All authors read and approved the final manuscript.
Funding

Not applicable.

\section{Availability of data and materials}

All specimens measured are available at the Natural History Museum (NHM) at Tring, UK. Recordings are available at the public sound library xeno-canto (www.xeno-canto.org), the Macaulay Sound Library (http://macaulaylibrary .org), the Avian Vocalizations Center (avocet.integrativebiology.natsci.msu. edu), and the Internet Bird Collection (www.hbw.com/ibc). A total of 26 recordings are provided by one of us (JAE; available upon request).

\section{Ethics approval and consent to participate}

Not Applicable.

\section{Consent for publication}

Not Applicable.

\section{Competing interests}

The authors declare that they have no competing interests.

\section{Author details}

${ }^{1}$ Bryn Mawr College, Department of Biology, 101 N Merion Ave, Bryn Mawr, PA 19010, USA. ${ }^{2}$ Department of Biological Sciences, National University of Singapore, 16 Science Drive 4, Singapore 117558 , Singapore. ${ }^{3}$ A-3A-5, Casa Indah I, Persiaran Surian, 47810 Petaling Jaya, Malaysia.

Received: 11 June 2020 Accepted: 13 October 2020

Published online: 28 October 2020

\section{References}

Alström P, Rasmussen PC, Xia C, Gelang M, Liu Y, Chen G, et al. Taxonomy of the White-browed Shortwing (Brachypteryx montana) complex on mainland Asia and Taiwan: an integrative approach supports recognition of three instead of one species. Avian Res. 2018;9:34.

Clements JF, Schulenberg TS, lliff MJ, Billerman SM, Fredericks TA, Sullivan BL, et al. The eBird/Clements Checklist of Birds of the World: v2019. https:// www.birds.cornell.edu/clementschecklist/download/. Accessed 23 May 2020.

Collar NJ, del Hoyo J, Jutglar F. The number of species and subspecies in the Red-bellied Pitta Erythropitta erythrogaster complex: a quantitative analysis of morphological characters. Forktail. 2015;31:13-23.

Cros E, Rheindt FE. Massive bioacoustic analysis suggests introgression across Pleistocene land bridges in Mixornis tit-babblers. J Ornithol. 2017;158:407-19.

del Hoyo J, Collar NJ. HBW and BirdLife International Illustrated Checklist of the Birds of the World Volume 2: Passerines. Barcelona: Lynx Edicions; 2016.

Dickinson EC. The Howard and Moore complete checklist of the birds of the world. Version 4.0 (Downloadable checklist). 2014. https://www.howar dandmoore.org. Accessed 23 May 2020.

Dong L, Wei M, Alström P, Huang X, Olsson U, Shigeta Y, et al. Taxonomy of the Narcissus Flycatcher Ficedula narcissina complex an integrative approach using morphological, bioacoustic and multilocus DNA data. Ibis. 2015;157:312-25.

Eaton JA, Rheindt FE. New avifaunal records from the Flores Sea islands, Indonesia, including a novel Phylloscopus leaf warbler. BirdingASIA. 2017;28:97-106.

Eaton JA, van Balen B, Brickle NW, Rheindt FE. Birds of the Indonesian Archipelago: Greater Sundas and Wallacea. Barcelona: Lynx Edicions; 2016.

Ericson PGP, Qu Y, Rasmussen PC, Blom MPK, Rheindt FE, Irestedt M. Genomic differentiation tracks earth-historic isolation in an Indo-Australasian archipelagic Pitta (Pittidae; Aves) complex. BMC Evol Biol. 2019;1 1:151.

Erritzoe J, de Juana E. Elegant Pitta (Pitta elegans). In: del Hoyo J, Elliott A, Sargatal J, Christie DA, de Juana E, editors. Handbook of the birds of the world alive. Barcelona: Lynx Edicions; 2020. https://www.hbw.com/node/57577 Accessed 23 May 2020.

Gill F, Donsker D, Rasmussen P. IOC World Bird List (v10.1). 2020.

Gooddie C. The jewel hunter. New Jersey: Princeton University Press; 2010. 
Gwee CY, Eaton JA, Garg KM, Alström P, van Balen S, Hutchinson RO, et al. Cryptic diversity in Cyornis (Aves: Muscicapidae) jungle-flycatchers flagged by simple bioacoustic approaches. Zool J Linn Soc. 2019;186:725-41.

Handbook of the Birds of the World and BirdLife International. Handbook of the Birds of the World and BirdLife International digital checklist of the birds of the world. Version 4. 2019. Available at https://datazone.birdlife org/userfiles/file/Species/Taxonomy/HBW-BirdLife_Checklist_v4_Dec19 .zip. Accessed 23 May 2020.

Harris JBC, Rasmussen PC, Yong DL, Prawiradilaga DM, Putra DD, Round PD, et al. A new species of Muscicapa flycatcher from Sulawesi, Indonesia. PLOS ONE. 2014;9:e112657.

Irestedt M, Fabre PH, Batalha-Filho H, Jønsson KA, Roselaar CS, Sangster G, et al. The spatio-temporal colonization across the Indo-Pacific by a'great speciator' (Aves, Erythropitta erythrogaster). Proc Roy Soc London-B Biol Sci. 2013;280:20130309.

Irestedt M, Ohlson J, Zuccon D, Källersjö M, Ericson PGP. Nuclear DNA from old collections of avian study skins reveals the evolutionary history of the Old World suboscines (Aves: Passeriformes). Zool Scr. 2006;35:567-80.

Isler Morton L, Isler Phyllis R, Whitney B. Use of vocalizations to establish species limits in Antbirds (Passeriformes: Thamnophilidae). Auk. 1998;115:577-90.

Kroodsma DE, Byers BE. The function(s) of bird song. Am Zool. 1991;31:318-28.

Mayr E, Ashlock P. Principles of systematic zoology. New York: McGraw-Hill; 1991.

Mayr E. Systematics and the origin of species, from the viewpoint of a zoologist. Cambridge: Harvard Univ. Press; 1942.

Mayr E. Principles of systematic zoology. New York: McGraw-Hill; 1969.

Mayr E. What is a species, and what is not? Philos Sci. 1996;63:262-77.

Miller EH, Areta J, Jaramillo A, Imberti S, Matus R. Snipe taxonomy based on vocal and non-vocal sound displays: the South American Snipe is two species. Ibis. 2020;162:968-90.

Nemeth E, Brumm H. Birds and anthropogenic noise: are urban songs adaptive? Am Nat. 2010;176:465-75.

Nemeth E, Pieretti N, Zollinger SA, Geberzahn N, Partecke J, Miranda AC, et al. Bird song and anthropogenic noise: vocal constraints may explain why birds sing higher-frequency songs in cities. Proc Roy Soc B-Biol Sci. 2013;280:20122798.

Ng EYX, Eaton JA, Verbelen P, Hutchinson RO, Rheindt FE. Using bioacoustic data to test species limits in an Indo-Pacific island radiation of Macropygia cuckoo doves. Biol J Linn Soc. 2016;118:786-812.
$\mathrm{Ng} \mathrm{S}$, Rheindt FE. Species delimitation in the White-faced Cuckoo-dove (Turacoena manadensis) based on bioacoustic data. Avian Res. 2016;7:2.

Pratt TK, Bruce MB. Birds of New Guinea. 2nd ed. New Jersey: Princeton University Press; 2014.

R Core Team. R: A language and environment for statistical computing. Vienna, Austria: R Foundation for Statistical Computing; 2019. https://www.Rproject.org/.

Rasmussen PC, Allen DNS, Collar NJ, DeMeulemeester B, Hutchinson RO, Jakosalem PGC, et al. Vocal divergence and new species in the Philippine Hawk Owl Ninox philippensis complex. Forktail. 2012;28:1-20.

Rheindt FE, Prawiradilaga DM, Ashari H, Suparno, Gwee CY, Lee GWX, et al. A lost world in Wallacea: Description of a montane archipelagic avifauna. Science. 2020;367:167-70

Rheindt FE, Norman JA, Christidis L. DNA evidence shows vocalizations to be a better indicator of taxonomic limits than plumage patterns in Zimmerius tyrant-flycatchers. Mol Phylogenet Evol. 2008;48:150-6.

Rheindt FE, Eaton JA, Verbelen F. Vocal trait evolution in a geographic leapfrog pattern: speciation in the Maroon-Chinned Fruit Dove (Ptilinopus subgularis) complex from Wallacea. Wilson J Ornithol. 2011;123:429-40.

Rheindt FE, Eaton JA. Biological species limits in the Banded Pitta Pitta guajana. Forktail. 2010;26:86-91.

Robin W, Vishnudas CK, Gupta P, Rheindt FE, Hooper DM, Ramakrishnan $\mathrm{U}$, et al. Two new genera of songbirds represent endemic radiations from the Shola Sky Islands of the Western Ghats. India BMC Evol Biol. 2017;17:31.

Sangster G, Rozendaal FG. Systematic notes on Asian birds. Territorial songs and species-level taxonomy of nightjars of the Caprimulgus macrurus complex, with the description of a new species. Zool Verh Leiden. 2004;350:7-45.

Sarr AC, Husson L, Sepulchre P, Pastier AM, Pedoja K, Elliot M, et al. Subsiding Sundaland. Geology. 2019:47:119-22.

Trainor CR, Imanuddin A, Verbelen P, Walker JS. The birds of Wetar, Banda Sea: one of Indonesia's forgotten islands. BirdingASIA. 2009;10:78-93.

Wallace AR. The Malay Archipelago: The land of the orang-utan and the bird of paradise: A narrative of travel, with studies of man and nature. London: Macmillan; 1872.

White CMN, Bruce MD. The birds of Wallacea. BOU Checklist. London: British Ornithologists Union; 1986.
Ready to submit your research? Choose BMC and benefit from:

- fast, convenient online submission

- thorough peer review by experienced researchers in your field

- rapid publication on acceptance

- support for research data, including large and complex data types

- gold Open Access which fosters wider collaboration and increased citations

- maximum visibility for your research: over 100M website views per year

At BMC, research is always in progress.

Learn more biomedcentral.com/submissions 